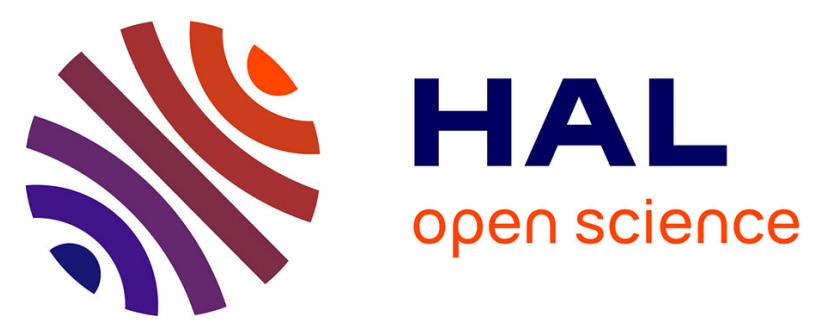

\title{
LTR-retrotransposons Tht1 and T135 markers reveal genetic diversity and evolutionary relationships of domesticated peppers
}

Sheh May Tam, Véronique Lefebvre, Alain Palloix, Anne-Marie Sage-Palloix, Corinne Mhiri, Marie Angele Grandbastien

\section{To cite this version:}

Sheh May Tam, Véronique Lefebvre, Alain Palloix, Anne-Marie Sage-Palloix, Corinne Mhiri, et al.. LTR-retrotransposons Tnt1 and T135 markers reveal genetic diversity and evolutionary relationships of domesticated peppers. TAG Theoretical and Applied Genetics, 2009, 119 (6), pp.973-989. 10.1007/s00122-009-1102-6 . hal-01203848

\section{HAL Id: hal-01203848 \\ https://hal.science/hal-01203848}

Submitted on 30 May 2020

HAL is a multi-disciplinary open access archive for the deposit and dissemination of scientific research documents, whether they are published or not. The documents may come from teaching and research institutions in France or abroad, or from public or private research centers.
L'archive ouverte pluridisciplinaire HAL, est destinée au dépôt et à la diffusion de documents scientifiques de niveau recherche, publiés ou non, émanant des établissements d'enseignement et de recherche français ou étrangers, des laboratoires publics ou privés. 


\section{LTR-retrotransposons Tnt1 and T135 markers reveal genetic}

\section{diversity and evolutionary relationships of domesticated peppers}

Sheh May Tam ${ }^{1 *}$, Véronique Lefebvre ${ }^{2}$, Alain Palloix ${ }^{2}$, Anne-Marie Sage-Palloix ${ }^{2}$, Corinne Mhiri $^{1}$ and Marie-Angèle Grandbastien ${ }^{1 \S}$

${ }^{1}$ INRA, UR501 - Laboratoire de Biologie Cellulaire, Institut Jean-Pierre Bourgin, F-78026 Versailles cedex, France

${ }^{2}$ INRA, UR 1052, Unité de Génétique et Amélioration des Fruits et Légumes, Domaine SaintMaurice BP 94, F-84143 Montfavet cedex, France

*Present address: School of Science, Monash University Malaysia, Jalan Lagoon Selatan, Bandar Sunway, 46150, Selangor Darul Ehsan, Malaysia

${ }^{\S}$ corresponding author: Marie-Angèle Grandbastien

Email: gbastien@versailles.inra.fr

Telephone: 33 (1) 30833024

Fax: 33 (1) 30833099 


\section{Abstract}

Plant genetic resources often constitute the foundation of successful breeding programs. Pepper (Capsicum annuum L.) is one of the most economically important and diversely utilised Solanaceous crop species worldwide but less studied compared to tomato and potato. We developed and used molecular markers based on two copia-type retrotransposons, Tnt1 and T135, in a set of Capsicum species and wild relatives from diverse geographical origins. Results showed that Tnt1 and T135 insertion polymorphisms are very useful for studying genetic diversity and relationships within and among pepper species. Clusters of accessions correspond to cultivar types based on fruit shape, pungency, geographic origin and pedigree. Genetic diversity values, normally reflective of past transposition activity and population dynamics, showed positive correlation with the average number of insertions per accession, while similar evolutionary relationships are observed to that inferred by previous karyosystematic studies, support the possibility that retrotransposons have contributed to genome inflation during Capsicum evolution.

Keywords: Capsicum, genetic diversity, retrotransposon, germplasm, evolutionary relationship 


\section{Introduction}

Pepper (Capsicum annuum L.) is one of the most economically important and diversely utilised vegetable crop species worldwide. Capsicum is a genus of about 25 species in the Solanaceae family and consists of annual and perennial herbs or shrubs native from South and Central America, including the Galapagos islands (Walsh and Hoot 2001). Capsicum annuum is grown worldwide and four additional species are commonly cultivated in south-central America, the Caribbean and Africa, namely C. baccatum, C. pubescens, C. frutescens and C. chinense (Pickersgill 1997). Though dominating as a hot spice, pepper has a variety of usages, either consumed fresh or is cooked/preserved and dried, used as food dyes, bred as ornamental plants and also provide the important ingredient (capsaisin) for the drug/chemical industry (Djian-Caporalino et al. 2006). To date, different kinds of molecular markers such as isozymes, RFLP, RAPD, AFLP and SSRs have all been successfully used to complement traditional morphological studies of Capsicum (Kwon et al. 2005; Lefebvre 2005).

Agriculture productivity and sustainability are highly dependent on secured access to genetic resources, as they often constitute the foundation of successful breeding programs. Breeding strategies make use of plant accessions of crops, wild relatives (landraces) or mutants maintained at genetic or germplasm centres with aims to increase crop production and quality, ascertain sources for transfer of beneficial traits such as disease resistance, abiotic stress tolerance and other useful biological traits. Molecular marker techniques now routinely provide highly reliable information in practical and efficient manners for use in the analysis of genetic diversity; generating invaluable data for plant breeding, crop improvement and germplasm management and conservation (Hammer et al. 2003); such as in cultivar protection, establishment of core collections, choice of parental lines for crossings, marker-assisted selection, variety identification (protection) and hybrid purity in the 


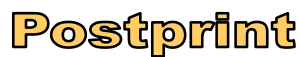

Version définitive du manuscrit publié dans / Final version of the manuscript published in : Theoretical and Applied Genetics,

2009, vol.119, no.6, pp 973-989. DOI:10.1007/s00122-009-1102-6

seed industry. Therefore, developing novel and improving current technical approaches applicable in the characterization and management of biodiversity are always required and ongoing.

Transposable elements are known to play important roles in genome evolution - affecting changes in physical genome size, generating chromosomal rearrangements and natural genetic diversity, altering the expression and function of genes and even serving molecular functions such as telomeres, neo-centromeres and promoters (Bennetzen 2002; Biemont and Vieira 2006; Kashkush et al. 2003; Vershinin et al. 2003). In higher plants, LTR (long terminal repeat) retrotransposons are abundant, amplifying to such high levels as to compose over $60 \%$ and over $80 \%$ of the maize and wheat genomes respectively (Bennetzen 2002, 2005). The predominance of LTR retrotransposons is because they do not excise as part of transposition and thus, generate stable polymorphic insertions that may be consequently exploited as molecular markers (Leigh et al. 2003). SSAP (Sequence-Specific Amplification Polymorphism) (Waugh et al. 1997) is the first described and perhaps the most utilised among several recently developed retrotransposon-based molecular marker techniques, which also includes copia-SSR, IRAP, REMAP and RBIP (Kalendar and Schulmann 2006). SSAP is a special marker system in its dual-functionality - useful as a tool to assess genetic diversity and, rather uniquely, SSAP data also permit comparative studies on the distribution of retrotransposon insertions, and it is this ability to track genomic changes caused by transposition activity that offers remarkable insights into actual evolutionary processes that generate genomic diversity. In addition, SSAP has been reported to be very useful in studies of genetic diversity, genetic relationships and linkage mapping for certain crop species (Ellis et al. 1998; Gribbon et al. 1999; Leigh et al. 2003; Pearce et al. 2000; Porceddu et al. 2002; Vershinin et al. 2003; Yu and Wise 2000; for review, see Tam et al. 2007a).

Solanaceae is a family with many crop species and is relatively well studied for retrotransposons, from the detection of the first active LTR retrotransposon Tnt1A of tobacco (Grandbastien et al. 1989) to subsequent studies in tomato (Costa et al. 1999; Rogers and Pauls 2000), potato (Manetti et al. 2007) and aubergine (C Mhiri, pers. comn.). We had previously found 


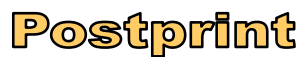

Version définitive du manuscrit publié dans / Final version of the manuscript published in : Theoretical and Applied Genetics, 2009, vol.119, no.6, pp 973-989. DOI:10.1007/s00122-009-1102-6

SSAP to be highly useful for studying genomic changes in allotetraploid tobacco (Melayah et al. 2004; Petit et al. 2007), genetic diversity within small collections of tomato and pepper from a private company (Tam et al. 2005) and genetic relationships and linkage mapping in Solanum subspecies Lycopersicon, revealing interesting insights on the distribution and interaction of these ubiquitous elements with their hosts (Tam et al. 2007b). In this study, we are interested in adapting the utility of the SSAP technique to study a representative set of Capsicum accessions maintained at the INRA-Montfavet (France) germplasm centre. This particular germplasm collection includes mainly traditional open-pollinated cultivars from all over the world, belonging to the five cultivated species of Capsicum, and their wild relatives (Sage-Palloix et al. 2007). Results of this study demonstrate that SSAP is a highly polymorphic, useful multi-locus molecular marker tool for the genus Capsicum. Analysis of the distributions of retrotransposon based markers also contributes to the better understanding of evolutionary relationships and genome evolution of Capsicum spp.

\section{Materials and methods}

Plant Material

A set of 86 accessions (Table 1) from the germplasm collection at INRA Montfavet (France) was used in this study. It comprised of seven species of Capsicum with a majority of the accessions belonging to the cultivated species C. annuum and wild relatives (C. annuum var grabriusculum). Cultivated inbred lines of $C$. frutescens, C. chinense, C. pubescens, C. baccatum and two wild species represented by one accession each respectively (C. chacoense and C. eximium) were also included in the study. The C. annuum accessions were chosen to represent the widest diversity in geographic origins; and fruit shapes were coded according to IPGRI, AVRDC and CATIE (1995). Plants were all grown under similar conditions in the greenhouse and five individuals per accession were collected for DNA extraction. Plant DNA was extracted from dried leaf material following the 


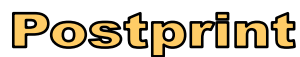

Version définitive du manuscrit publié dans / Final version of the manuscript published in : Theoretical and Applied Genetics,

2009, vol.119, no.6, pp 973-989. DOI:10.1007/s00122-009-1102-6

protocol of the Qiagen DNeasy® 96 Plant Kit (Qiagen SA, Courtaboeuf, France). Isolated total

DNAs from the five individuals were pooled per accession for further treatment.

Sequence-specific amplified polymorphism (SSAP)

Three retrotransposon primer sets were generated from two LTR-retrotransposon families, namely Tnt1 and T135, using the primer combinations Tnt1-C00 (Csp6), Tnt1-E00 and T135-E00 (EcoRI) described in Tam et al. (2005). The SSAP assays were carried out following the protocol previously described (Tam et al. 2005).

Data Analysis

All SSAP bands were visually scored as present (1) or absent (0) across the seven species of Capsicum (86 accessions) and among accessions within each species. Individual binary matrices were built for each primer combination. For SSAP analyses, detected bands of distinct sizes are treated as independent insertions and scored as a character-type.

Genetic relationships between accessions within and among Capsicum species were inferred using genetic distance. Mantel's test (Liedloff 1999) was used to assess the strength of correlation between two observed distance matrices and the statistic tested for significance against 1000 random permutations. A combined binary dataset from the merger of the three individual primer datasets was analysed using PAUP* 4.10 (Swofford 2002). Pairwise distances were computed using the mean character difference option which only takes into consideration mismatches and the Neighbor-Joining (Saitou and Nei 1987) algorithm clustered pairwise distances using the minimum evolution option. Clade support was estimated by 1000 Neighbor-Joining bootstrap replications. The SSAP-NJ tree was first rooted at midpoint of the longest path connecting two taxa in the network ("midpoint rooting", Kitching et al. 1998) and secondly, rooted with C. eximium based on 


\section{P๑S}

Version définitive du manuscrit publié dans / Final version of the manuscript published in : Theoretical and Applied Genetics,

2009, vol.119, no.6, pp 973-989. DOI:10.1007/s00122-009-1102-6

results of a previous phylogenetic study using atpB-rbcL and waxy genes (Walsh and Hoot 2001).

We also applied the Neighbor Net network on the distance data using the program SplitsTree 4.0 (Huson and Bryant 2006). This distance-based method displays character conflict (data incompatibilities) that may be used to explore complex within (and inter-) species evolutionary processes that will not be well represented by a strictly dichotomous phylogenetic tree (Morrison 2005).

Bayesian clustering analyses were also performed using the program STRUCTURE version 2.2, which permitted the use of dominant markers (Falush et al. 2007; Pritchard et al. 2000). The program uses multilocus genotypes to infer population structure, identify distinct genetic populations, assign individuals to populations and identify admixed individuals assuming $\mathrm{K}$ number of populations (Falush et al. 2007). K was allowed to range from one to ten for the interspecific dataset (all accessions), and one to twenty two for the dataset comprising of $C$. annuum accessions only, based on the maximum number of geographic origin of the accessions. Two or more replicate runs were made for each $\mathrm{K}$ value using the correlated allele frequency model (prior mean $=0.01$; prior $\mathrm{SD}=0.05$ and Lambda $=1.0$ ), with a burn-in period of 10,000 iterations followed by a run length of 100,000 iterations.

Retrotransposons insertion frequencies for individual and combined datasets for each species were estimated as percentage polymorphism and gene diversity $\left(\mathrm{H}_{\mathrm{e}}\right)$, where $\mathrm{H}_{\mathrm{e}}$ is the total genetic diversity computed over all loci (Nei 1973) using POPGENE vs 1.31 (Yeh and Boyle 1997). For dominant markers, $\mathrm{H}_{\mathrm{e}}=1-\sum_{\mathrm{i}}\left(\mathrm{p}_{\mathrm{no}}{ }^{2}+\mathrm{p}_{\mathrm{n} 1}{ }^{2}\right)$, with $\mathrm{p}_{\mathrm{no}}+\mathrm{p}_{\mathrm{n} 1}=1$ and where $\mathrm{p}_{\mathrm{no}}$ and $\mathrm{p}_{\mathrm{n} 1}$ represent respectively the frequencies of the absence and presence of alleles of the marker $n$, with $n$ being comprised in the set of the i markers (Porceddu et al. 2002). In addition, the number of speciesspecific insertions (present in accessions of a single species regardless of frequency) was calculated from individual retrotransposon datasets. Phylogenetic Independent Contrasts (PIC), which provide statistical independence when comparing across related taxa were carried out using CAIC (Purvis and Rambaut 1995) with the option of equal branch lengths to estimate relationships between 


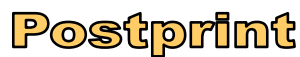

Version définitive du manuscrit publié dans / Final version of the manuscript published in : Theoretical and Applied Genetics,

2009, vol.119, no.6, pp 973-989. DOI:10.1007/s00122-009-1102-6

percentage polymorphism and gene diversity with average number of insertions per accession for individual retrotransposon datasets. Relative numbers of retrotransposon insertions were estimated by directly counting the number of bands on the SSAP gels. The phylogeny of Capsicum was coded in CAIC based on atpB-rbcL and waxy DNA sequence evidence (Walsh and Hoot 2001).

\section{Results}

Distribution of Tnt1 and T135 retrotransposon markers in seven Capsicum spp

We performed SSAP with the three primer sets Tnt1-C00, Tnt1-E00 and T135-E00, on a set of 86 cultivated and wild accessions comprised of seven species of Capsicum (Table 1). Analysis of the three SSAP primer sets scored across the seven species yielded a total of 195 bands, of which $192(98.46 \%)$ are polymorphic among the 86 accessions (Table 2). Species-specific insertions recorded from each retrotransposon dataset for the seven species studied (Table 2) showed Tnt1C00 having 11 species-specific insertions from a total of 95 scored bands (11.58\%), Tnt1-E00 showed 7 out of 50 (14\%), whilst T135-E00 had 6 of 50 species-specific insertions (12\%). Mantel's test of pairwise distances between the accessions revealed significantly high correlations $(\mathrm{p}<0.01)$ between the datasets (Tnt1-C00 and T135-E00, r= 0.9209; Tnt1-C00 and Tnt1-E00, r=0.9074 and T135-E00 and Tnt1-E00, $\mathrm{r}=0.9044)$. Therefore, the three datasets were combined and used to infer interspecific relationships of Capsicum.

The combined SSAP-NJ tree is well resolved and shows well-supported groups corresponding to the different species. The SSAP-NJ tree rooted using the midpoint rooting function (Fig. 1a) shows two main groups, one consisting of $C$. chacoense sister to the $C$. frustescens, C. chinense and C. annuum, and a second group consisting of C. baccatum as sister taxa to C. eximium and together, being more closely related to C. pubescens. Species groups on the tree are well defined except for the displacement of two accessions of $C$. frutescens $(\mathrm{C} 88, \mathrm{C} 89)$, 


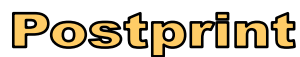

Version définitive du manuscrit publié dans / Final version of the manuscript published in : Theoretical and Applied Genetics,

2009, vol.119, no.6, pp 973-989. DOI:10.1007/s00122-009-1102-6

which clustered with $C$. chinense. Branch lengths between accessions of $C$. annuum are relatively

shorter compared to the rest of the species. All Capsicum accessions used in this study are cultivated populations or cultivars and have undergone breeding selection, except for five wild accessions (see Table 1). Interestingly, the two wild C. annuum var glabriusculum accessions (C25, Turrialba and C52, Piquin) appear in basal positions to the cultivated C. annuum, and the wild C. baccatum var baccatum accession (C91) also occupies a basal position compared to cultivated $C$. baccatum var pendulum accessions. The SSAP-NJ tree rooted with C. eximium (Additional file 1) shows C. baccatum as sister to the remainder species studied. Capsicum pubescens is sister to $C$. chacoense, which in turn is sister to a distinct group consisting of C. annuum together with the sister taxa of C. chinense and C. frutescens.

Neighbor Net analysis of the 86 accessions (Goodness of Fit $=94.72)$ produced a network that is remarkably similar to the NJ tree whereby all accessions generally resolved according to their species (Fig. 2). However, several character conflicts are detected, notably among C. pubescens, C. baccatum and within C. frutescens where one accession (C89) clearly resolved with C. chinense. When the 86 accessions of Capsicum were analysed for genetic structure, the highest likelihood value (Ln P(D) = -5204.05, averaged over two runs) was obtained when five genetically distinct groups were identified $(\mathrm{K}=5)$ (Table 3$)$. This reflects the high differentiation that exists between the species and corresponded well to the species delimitation of $C$. pubescens, $C$. baccatum, C. annuum, C. frutescens and C. chinense (Fig. 1b). A total of 15 (17.44\%) of the 86 accessions in the sample were categorised as having mixed genome, of particular interest are $C$. baccatum var baccatum (C91), C. eximium (C85), C. chacoense (C78) and C. annuum var glabriusculum C25 (Turrialba), which are all wild accessions (Fig. 1b). Interestingly, the C. frutescens accession (C89) that resolved in C. chinense on $\mathrm{NJ}$ and $\mathrm{NN}$ trees showed a genetic structure quite similar to C. chinense accessions 
Genetic diversity within Capsicum species

Genetic diversity values are further compared among four species, namely C. annuum (64 accessions), C. baccatum (eight accessions), C. chinense and C. frutescens (five accessions respectively) (Table 4). The number of bands scored from the combined SSAP datasets ranged from 84 for C. chinense to 130 for C. annuum. The highest percentage polymorphism is calculated from C. annuum (82.31\%) followed by C. frutescens, C. baccatum and lastly C. chinense (46.43\%). The group displaying the highest gene diversity $\left(\mathrm{H}_{\mathrm{e}}\right)$ value is $C$. frutescens $(0.276)$, followed by $C$. baccatum, C. annuum and finally, C. chinense (0.172).

Mean genetic distance recorded for C. annuum is lowest (0.146), followed by C. baccatum, C. chinense and highest for $C$. frutescens (0.390). The maximum genetic distance is estimated from C. frutescens (0.557), followed by C. annuum, C. baccatum and finally C. chinense (0.321). Capsicum annuum has the minimum estimated genetic distance (0.0236), followed by C. baccatum, C. chinense and lastly $C$. frutescens (0.189). Higher polymorphism rate (but lower $\mathrm{H}_{\mathrm{e}}$ value) in $C$. annuum is probably due to the greater number of accessions sampled from this species. The $C$. annuum collection was divided into two groups: pungent chilli peppers and sweet peppers (Table 4), the former having mean genetic distance estimated as 0.170 and sweet pepper lines, 0.141 .

Phylogenetic independent contrast (PIC) test values revealed significant positive correlations between genetic diversity values and average number of insertions per accession for two of the retrotransposon datasets (Table 5). A weak, significant positive correlation is detected between percentage polymorphism and average number of insertions per accession for T135-E00 (p $=0.084)$ whilst Tnt1-C00 showed significant positive correlation between gene diversity $\left(\mathrm{H}_{\mathrm{e}}\right)$ and average number of insertions per accession $(\mathrm{p}=0.007)$.

Genetic relationships within the C. annuum accessions 


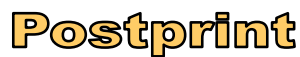

Version définitive du manuscrit publié dans / Final version of the manuscript published in : Theoretical and Applied Genetics, 2009, vol.119, no.6, pp 973-989. DOI:10.1007/s00122-009-1102-6

The SSAP-NJ tree shows accessions of the C. annuum resolving as a basal group followed by three distinct clusters (Clus1, which is sister to two more closely related clusters, Clus 2 and Clus3; Fig. 3a). Genetic relationships for C. annuum inferred from the SSAP-NJ tree show rather good coherence with pepper fruit size and with pepper fruit code (see Table 1). The six other Capsicum species studied here are all pungent, small/medium fruited accessions (Table 1), reflecting the lack of selection for sweet large fruits in these species. For C. annuum, large-fruited varieties mainly group in Clusters 1 and 3, and small/medium-fruited varieties mainly group in Cluster 2, as well as in the basal group. It is observed that the large sweet peppers in Cluster 1 are very closely related, whilst the small/medium varieties in Cluster 2 appear more diverse with relatively higher branch lengths (genetic distances). Square (1) and rectangular (2) pepper group in Cluster 1 of large sweet peppers, and to a lower extent in Cluster 3 that also contains the spherical peppers (6 and 7), which are used mainly for canned food. Elongated peppers (4 and 5), on the other hand, are found in groups of small/medium pungent peppers (basal group and Cluster 2). Finally, triangular peppers (3) are found dispersed amongst Cluster 2 and Cluster 3, as they are thought to derive either from reduction in size of quadrangular peppers or from proximal enlargement of elongated peppers.

The SSAP-NJ tree also reflects well information of known pepper pedigrees, both in terms of certain geographical origin and breeding programs. For instance, C64 (Milord) and C65 (Vania) belong to the same population derived from parental accessions C68 (Bastidon) and C39 (Carré d'Asti jaune), and all four accessions are closely related within Cluster 1. Cluster 1 also groups sweet peppers lines derived from traditional local populations (C45, C39, C48, C59) or contemporary selection (C36, C64, C65, C68, C63) from Western Europe. Cluster 2 groups pungent pepper types from ancient local populations of diverse geographical origins. Traditional small/medium-fruited Mexican cultivars (C19, C20, C21, C30, C32) group within the same subcluster, separated from traditional Turkish cultivars (C33, C34). Interestingly, however, some traditional Indian (C26 and C28), as well as Ethiopian (C37) and Chinese (C35) varieties resolved 


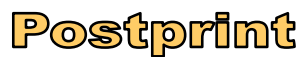

Version définitive du manuscrit publié dans / Final version of the manuscript published in : Theoretical and Applied Genetics, 2009, vol.119, no.6, pp 973-989. DOI:10.1007/s00122-009-1102-6

close to the Mexican varieties, suggesting that the later four varieties might have origins from

Mexican populations now dispersed into diverse regions of the world. Cluster 3 clearly include traditional sweet fruited cultivars from Mediterranean Europe (C05, C04, C06, C07, C09, C12, $\mathrm{C} 11, \mathrm{C} 02)$, and tightly groups three varieties $(\mathrm{C} 15, \mathrm{C} 24$ and $\mathrm{C} 18)$ issued from a single Brazilian genetic program selecting for viral resistance together with an US accession C54. In addition, Cluster 3 also contain C01 (Yolo Wonder), C08 (Yolo Y), C29 (Florida VR2) and C54 (ECW), all issued from the same genetic pool (American "blocky" types). More disparate is the presence in Cluster 3 of accessions from different geographical origins such as C38 (China), C42 (Cuba), C16 and C13 (Russia), suggesting relationships based on common exchanges.

For the C. annuum accessions, the clustering approach implemented by the Structure program inferred four source populations, with the probability function peaking at $\mathrm{K}=4(\mathrm{LnP}(\mathrm{D})=-$ 2886.7 averaged over three runs), and values of $\mathrm{Ln} \mathrm{P}(\mathrm{D})$ did not improve significantly for $\mathrm{k}>4$ (Table 3). The distribution of the inferred four subpopulations appears to correspond to a certain degree with the clusters inferred by the Neighbor Joining method (Fig. 3b). No non-admixed accession was identified; only nearly non-admixted ancestry was inferred for many individuals corresponding to the four source populations. Certain accessions represent the best of the nonadmixted source population; they are genetically distant from each other according to the SSAP NJ tree. C25 (Turrialba) is distant from other C. annuum accessions and is considered as the wild ancestor of C. annuum species. C52 (Piquin) is the wild accession that could well represent the basal group. C68 could represent the best among the large sweet cultivars of Cluster 1. C03 (Cerise) could represent both the branches at the base of Cluster 2 and Cluster 3.

\section{Discussion}




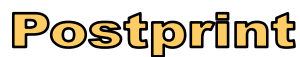

Version définitive du manuscrit publié dans / Final version of the manuscript published in : Theoretical and Applied Genetics, 2009, vol.119, no.6, pp 973-989. DOI:10.1007/s00122-009-1102-6

Interspecific relationships of domesticated peppers inferred from insertions of Tnt1 and T135 retrotransposons

Three combined SSAP datasets generated using the Tnt1 and T135 families of LTRretrotransposons successfully inferred interspecific relationships among seven species of Capsicum. Molecular phylogeny of Capsicum has not been as extensively studied compared to other Solanaceous genera such as Solanum subspecies Lycopersicon or Nicotiana. The SSAP-NJ tree is well resolved and shows several well-supported clusters useful for species delimitation. In general, the tree topology shows good agreement with botanical classifications issued from geographical, ethnobotanical and cytogenetic data (Djian-Caporalino et al. 2006). Results from SSAP analysis is also compatible with previous studies, such as the molecular phylogenetics study of 11 species of Capsicum based on combined sequences of atpB-rbcL and waxy (Walsh and Hoot 2001). The SSAP-NJ tree clearly distinguishes the $C$. annuum-C. chinense- $C$. frutescens complex from other Capsicum species as illustrated by Eshbaugh et al. (1983). Capsicum chinense and C. frutescens resolved as sister taxa to the highly supported group of C. annuum. All accessions clustered according to species except for two accessions of $C$. frutescens, which resolved basal to $C$. chinense, inadvertently supporting past suggestions to combine these two species because of morphological similarities and possible inter crossing between these two species (Djian-Caporalino et al. 2006). It was also proposed that $C$. frutescens could be the putative ancestor of $C$. chinense (Eshbaugh et al. 1983). Based on the position of the C. frutescens C89 accession on NJ and NN trees, genetic structure similarity with $C$. chinense accessions and recent morphological re-analysis, we are able to reclassify C89 as C. chinense (CHI7) (Table 1). Capsicum chacoense resolved on the SSAP-NJ tree as the sister species to the C. annuum -C. frutescens-C. chinense complex, and this is in agreement with the morphological similarity of these taxa and evidence based on enzymatic studies and atpB-rbcL and waxy sequences (McLeod et al. 1982; Onus and Pickersgill 2004; Walsh and Hoot 2001). 


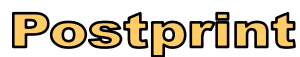

Version définitive du manuscrit publié dans / Final version of the manuscript published in : Theoretical and Applied Genetics, 2009, vol.119, no.6, pp 973-989. DOI:10.1007/s00122-009-1102-6

The grouping of C. baccatum, C. eximium and C. pubescens on the SSAP-NJ tree is coherent with previously reported species relationships (Nagy et al. 2007; Park et al 2000), with C. baccatum appearing as a group on its own while C. eximium and C. pubescens (together with $C$. cardenasii) forming a basal complex group with purple flowers (McLeod et al. 1982; Nagy et al. 2007; Onus and Pickersgill 2004). However, the atpB-rbcL - waxy and microsatellite markers (SSR) based trees positioned C. baccatum as sister to C. chacoense and together, they formed the sister group to the C. annuum-C. frutescens-C. chinense complex which is concordant with crossing compatibility between these species. The SSAP-NJ tree rooted with $C$. eximium showed $C$. pubescens is sister to C. chacoense and the C. frutescens-C. chinense-C.annuum group, and this genetic relationships is different from what was reported by most previous studies, except for an earlier study of six Capsicum species using RAPD markers (Rodriguez et al. 1999) that showed agreement with SSAP in species relationships.

To further explore genetic relationships, the Neighbor-Net network was used to depict character-states pattern conflict in the SSAP data. Reticulations in a character display network can be interpreted to represent data uncertainty/error (mistaken homology, model heterogeneity or insufficient data), actual homoplasy in the phylogeny or evolutionary events that involved gene exchange between organisms such as recombination and hybridisation (Huson and Bryant 2006; Morrison 2005). Neighbor-Net indicated prominent reticulate relationships between accessions of C. pubescens (C92, C93), C. baccatum var. baccatum (C91) and C. frutescens (C88), in addition to many splits (uncertainty) seen amongst the C. annuum lines. Model-based structure analysis revealed the presence of five populations for the Capsicum accessions studied, of which individuals mostly corresponded to the species identified from botanical traits. Interestingly, the different position of C. pubescens inferred on the SSAP-NJ tree can be further understood by observations that NeighborNet displayed reticulation for C92 and C93 but structure analysis showed both to possess non-admixed genotypes. The genotype of $C$. pubescens, however, was also detected in both 


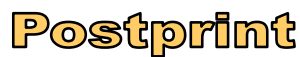

Version définitive du manuscrit publié dans / Final version of the manuscript published in : Theoretical and Applied Genetics, 2009, vol.119, no.6, pp 973-989. DOI:10.1007/s00122-009-1102-6

C. eximium and C. chacoense, and this could explain its position on the SSAP-NJ tree which grouped accessions based strictly on genetic similarity in a dichotomous fashion.

Phylogenetic (Neighbor Joining and NeighborNet) and model-based structure analyses of the sampled Capsicum accessions also showed that the most admixed genotypes correspond to the wild accessions (C78, C85, C91, C25, and C87), which include alleles from two to four distinct species. Another case is the $C$. frutescens accession C88 which displays primitive (wild) traits such as very small and dehiscent fruits, it also showed a mixed genotype. This suggests that wild accessions share diverse alleles, which were subsequently fixed either through speciation and/or further domestication. SSAP data also show that the germplasm collection cannot be wholly characterised based on phenotypic (morphological) characters alone. For example, individuals of two populations corresponded well to their assigned species (C. baccatum and C. annuum), though both showed small groups with admixed genotypes (25\% and $9.4 \%$ respectively). The remainder three populations, however, included individuals that were assigned to separate species (especially between $C$. chinense and $C$. frutescens) and accessions of $C$. pubescens were clustered with $C$. eximium and C. chacoense.

A possible explanation for the SSAP inferred genetic relationship is that the evolutionary history of the Capsicum species is influenced by the activity of the LTR-retrotransposons since Capsicum is known to have relatively large genomes (3753 to $4763 \mathrm{Mbp}$ ) (Bennett and Leitch 2005). Moscone et al. (2003) performed a karyosystematic study on 11 Capsicum species and reported that nuclear DNA content measurements in the genus demonstrated significant differences in genome size between taxa. The species studied were delimited as significant groups with characteristic genome sizes (1C value/genome size in $\mathrm{Mbp}$ ) and karyological data. Four species were included in the same Scheffe group with similar, comparatively low DNA amount and little heterochromatin displayed, namely C. chacoense $(3.35 \mathrm{pg} / 3283 \mathrm{Mbp}), \quad$ C. frutescens (3.4pg/3332Mbp), C. chinense (3.42pg/3352Mbp) and C. annuum var. annuum (3.38pg/3312Mbp). The next group $(3.71 \mathrm{pg} / 3636 \mathrm{Mbp})$ consisting of C. baccatum var. baccatum $(3.71 \mathrm{pg} / 3636 \mathrm{Mbp})$, C. 


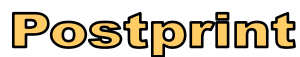

Version définitive du manuscrit publié dans / Final version of the manuscript published in : Theoretical and Applied Genetics, 2009, vol.119, no.6, pp 973-989. DOI:10.1007/s00122-009-1102-6

baccatum var. pendulum (3.68pg/3606Mbp) and C. baccatum var. umbilicatum (3.76pg/3685Mbp)

showed increased DNA content and more complex heterochromatin banding pattern, corroborating that $C$. baccatum should have a separate placement from the species mentioned. Capsicum eximium (4.06pg/3979Mbp) was shown to be intermediate in DNA content between C. baccatum and the comparatively larger genome and larger amount of complex patterned heterochromatin of $C$. pubescens $(4.47 \mathrm{pg} / 4381 \mathrm{Mbp})$ and thus C. eximium, C. baccatum and C. pubescens were placed into their own respective Scheffe groups. Therefore, it is of interest that the SSAP-NJ tree displayed similar genetic relationships among the Capsicum species as suggested by Moscone et al. (2003), reflecting the close relationship of $C$. chacoense to the $C$. frutescens- $C$. chinense- $C$. annuum complex and the position of C. eximium in between C. baccatum and C. pubescens. However, we note that no correlation is apparent between DNA content and copy numbers of the two LTRretrotransposons studied here.

Genetic diversity and relationships of Capsicum annuum

The SSAP technique could be successfully applied to characterise the genetic diversity within Capsicum accessions. Highly polymorphic SSAP markers generated DNA profiles that showed no duplicate accession within the collection studied. Identification and elimination of duplicated accessions in a collection is extremely useful in terms of time and cost saved in germplasm maintenance and breeding programs (Rodriguez et al. 1999). Important parameters normally considered in studies relating to crop genetic diversity include the level of genetic variation within populations/groups and the extent of genetic divergence among populations/groups. Molecular markers that detect high levels of polymorphism between cultivars help improve the efficiency and accuracy of genetic similarity estimates (Ribeiro-Carvalho et al. 2004). The SSAP markers show that the pepper collection possesses a high degree of polymorphism $(82.31 \%)$ and a moderate value of gene diversity $\left(\mathrm{H}_{\mathrm{e}}=0.1805\right)$. 


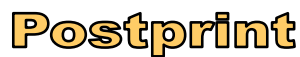

Version définitive du manuscrit publié dans / Final version of the manuscript published in : Theoretical and Applied Genetics, 2009, vol.119, no.6, pp 973-989. DOI:10.1007/s00122-009-1102-6

SSAP show that the C. annuum samples display 1.8-fold higher polymorphism levels than

the C. chinense samples, while the C. frutescens and C. baccatum samples are intermediate (1.1fold and 1.4-fold respectively), albeit sample sizes being not balanced between species. However, in terms of gene diversity $\left(\mathrm{H}_{\mathrm{e}}\right)$, C. frutescens possess the highest variation, and are 1.3-, 1.5- and 1.6folds higher than C. baccatum, C. annuum and C. chinense respectively. Other studies had also reported that $C$. annuum possess intermediate to moderately high levels of genetic variation for a self-pollinating crop species, using RFLP, RAPD, AFLP and morphological traits (Lefebvre et al. 1993; Lefebvre et al. 2001); AFLP and RAPD (Lanteri et al. 2003); morphology and AFLP (Geleta et al. 2005). High genetic variation could be due to higher levels of outcrossing than normally expected (Tanksley 1984). In a study of an Italian landrace of pepper using RAPD and AFLP, it was observed that most variation was partitioned within, rather than between populations, and this was not consistent with the selfing breeding system of $C$. annuum but rather indicated a high level of outcrossing in the pepper landrace (Lanteri et al. 2003).

The SSAP-NJ tree shows a basal group closely related to three defined clusters - one cluster of pungent and two clusters of sweet (non-pungent) fruited peppers respectively. Pungent accessions are mostly small-medium and long fruited, which positioned basal to the sweet large peppers. Sweet large pepper types are separated in two clusters, suggesting origins from two distinct genetic pools, as confirmed by two markedly different types of genetic structure. Altogether, our data are informative and correlate with pepper fruit shape and/or with pedigrees and geographic origins, permitting potential determination of genetic pools. Both distance and model based analyses show that many accessions of $C$. annuum carry genetic evidence of some level of admixture within each of the four subpopulations inferred. This could be accounted for by the process of artificial selection and breeding carried out during the development of these lines. Introgression among different source subpopulations would create intermediate types that will not be easily distinguished at the phenotypic level, and is also difficult to visualize using a Neighbor Joining tree that is forced to represent the data into a simplified hierarchical structure. In particular, 


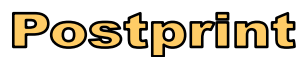

Version définitive du manuscrit publié dans / Final version of the manuscript published in : Theoretical and Applied Genetics,

2009, vol.119, no.6, pp 973-989. DOI:10.1007/s00122-009-1102-6

we were unable to relate the splitting of sweet-fruited cultivars in two clusters to geographic or pedigree information. Conversely, the subgroups within these clusters were more clearly related with geographic origin and pedigree information. For this pepper study, the results of the splits network and genetic structure analyses definitely present a more realistic and useful representation of the reticulate genetic relationships by allowing the visualization of shared (and conflicting) character states with individuals from other sources/groups.

Additional estimates of mean genetic distance of the pre-determined two groups in the pepper collection is also consistent with those reported by previous studies (Lefebvre et al. 1993; Lefebvre et al. 2001; Paran et al. 1998) where small-fruited cultivars were found to harbour higher degrees of genetic variation compared to the large fruited sweet cultivars, suggesting that smallfruited cultivars were selected from a larger genetic pool and suffered lower genetic bottleneck effects. Similarly, Lanteri et al. (2003) found little genetic variation in a landrace of elongated bell pepper type from North West Italy using RAPD and AFLP. In this study, the pungent chilli group, which contains small and long fruited accessions, has a higher mean genetic distance than sweet pepper lines.

Evolutionary dynamics of Tnt1 and T135 retrotransposons in the genome of Capsicum

At present, much is still unknown regarding the distribution of similar types of transposable elements among closely related species (Hawkins et al. 2006) even though transposable elements are ubiquitously present in the genomes of eukaryotic organisms. Our series of ongoing studies have successfully detected and compared insertions of Tnt1 and T135 (originally isolated from tobacco and tomato respectively) between different species in several genera of the Solanaceae (Manetti et al. 2007; Tam et al. 2005), indicating that these elements have persisted through the duration of speciation for long periods of time. Therefore, we can successfully develop insertionbased molecular markers that are transferable to other Solanaceous species. 


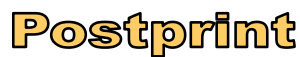

Version définitive du manuscrit publié dans / Final version of the manuscript published in : Theoretical and Applied Genetics, 2009, vol.119, no.6, pp 973-989. DOI:10.1007/s00122-009-1102-6

One important advantage of the SSAP technique is that genetic diversity values obtained by

SSAP indirectly permit detection of activity and maintenance of different retrotransposons in a particular set of hosts where higher diversity values are indicative of more recent transposition activities (Ellis et al. 1998; Gribbon et al. 1999; Kalendar et al. 1999; Vershinin et al. 2003). Elements can transpose at high frequency, with a rate ranging from $10^{-3}$ to $10^{-5}$ per element per generation (depending on element) compared with a nucleotide-base substitution rate of $10^{-8}$ to $10^{-9}$ per nucleotide per generation. Therefore, transposable elements are recognised as powerful sources of genetic diversity (Biemont and Vieira 2006). High rates of SSAP polymorphisms coupled with the identification of species-specific bands (unique bands, regardless of frequency) observed in this study both indicate that retrotransposition events have occurred during the speciation of Capsicum. Both Tnt1 and T135 have similar proportion of species-specific bands $(12.41 \%$ and $12 \%$ respectively), contributing to a notable proportion of natural diversity amongst genomes of the different Capsicum species. This finding supports the important role of retrotransposon activity in generating natural genetic diversity in the various lineages of Capsicum.

The evolutionary dynamics of transposable elements essentially reflect interactions between element proliferation and loss as a result of one or more opposing deterministic forces that includes selection acting through the host, genetic drift and self regulatory behaviour (Morgan 2001; Sniegowski and Charlesworth 1994; Wright and Schoen 1999). In this study, no apparent difference in lineage-specific amplification of retrotransposon is observed between Tnt1 and T135. No differences were detected in the average number of insertions per accession between the two wild (C. eximium, C. chacoense) and five cultivated Capsicum species (difference of only 1.03 fold), or between wild C. chacoense and the domesticated C.annuum-C. chinense-C. frutescens complex (1.06 fold) and between the one self-incompatible (C. eximium) and six inbreeding species (1.05 fold). Significant differences in copy number and insertion frequencies between species reflect a strong negative selection against retrotransposon insertions (or even slightly deleterious mutations) as a consequence of higher genetic load associated with inbreeding depression or domestication 


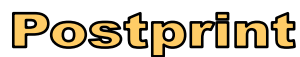

Version définitive du manuscrit publié dans / Final version of the manuscript published in : Theoretical and Applied Genetics, 2009, vol.119, no.6, pp 973-989. DOI:10.1007/s00122-009-1102-6

(Morgan 2001; Wright and Schoen 1999) or, inversely, higher accumulation of elements and at higher frequencies in selfers due to the influences of reduced recombination and effective population size (Wright et al. 2003). Also, retrotransposon insertions would not necessarily always prove useful for inferring host phylogeny. For instance, the Tnt1-ol13 retrotransposon population showed an extremely high number of insertion polymorphisms in Nicotiana, but no coherent interspecific phylogeny could be inferred (Melayah et al. 2004). Another example include the analysis of nine selected genotypes of sweet potato by SSAP, which revealed that the majority of the Ty1-copia transposon insertions were unique (33 to 64\%) with only few common bands detected (Berenyi et al. 2002). IRAP markers reportedly showed high levels of genetic diversity but did not discriminate individuals of Aegilops tauschii based on morphology, possibly due to different activity of retroelements (Saeidi et al. 2008). Hence, our results in Capsicum may be taken to indicate the selective neutrality of most of the insertions revealed by SSAP, suggesting that these insertions are well tolerated by the Capsicum host genomes.

Interestingly, our study revealed weak but significant positive correlations between genetic diversity values and the average number of insertions per accession for both Tnt1 and T135 in Capsicum. In contrast, in an earlier study, no significant correlation was detected between genetic diversity values and retrotransposon abundance in Solanum subsection Lycopersicon (Tam et al. 2007b). Comparative genomic studies have found significant correlation between retrotransposon abundance and genome size. In Gossypium, the major fraction of genome size variation observed within the genus was largely attributed to recent, lineage-specific amplification of one particular group of gypsy-like retrotransposon sequences, Gorge3 within the larger genome Gossypium species (Hawkins et al. 2006). For the legume Vicia pannonica, it was reported that the significant expansion of its genome size was mediated by the amplification of Ogre, a giant $25 \mathrm{~kb}$ Ty $3 /$ gypsy element which alone made up 38\% of the genome of this species (Neumann et al. 2006). The 2C DNA content of pepper is two- to four-fold greater than that of tomato but both species have similar chromosome number and gene content (Arumuganathan and Earle 1991). In their study of genome 


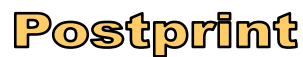

Version définitive du manuscrit publié dans / Final version of the manuscript published in : Theoretical and Applied Genetics, 2009, vol.119, no.6, pp 973-989. DOI:10.1007/s00122-009-1102-6

mapping in Capsicum, Livingstone et al. (1999) suggested that an increase in the size of pepper genome without apparent increase in gene content involved the expansion of heterochromatin and the increase in the amount of repeated DNA such as retrotransposons. The observed (weak) positive relationship between higher genetic diversity values (reflective of element activity) and increase in the number of insertions (copy number) together with the recorded high percentage of unique (species-specific) insertions (average 12.5\%), provide evidence for the active contribution of retrotransposon activities in generating a significant proportion of natural genetic diversity in the genome of Capsicum. It further strongly suggests the possibility that retrotransposons might have contributed to genome evolution (expansion) of Capsicum.

\section{Acknowledgements}

We are extremely grateful to Christian Parisod, Miki Okada, and Kietsuda Leungwilai for their helpful comments and suggestions. This study was funded by the FW6 EC TEGERM project EC-QLRT-1999-31502.

\section{References}

Arumuganathan K, Earle ED (1991) Nuclear DNA content of some important plant species. Plant Molecular Biology Reporter 9:211-215

Bennett MD, Leitch IJ (2005) Nuclear DNA Amounts in Angiosperms: Progress, Problems and Prospects. Annals of Botany 95:45-90

Bennetzen JL (2002) Mechanisms and rates of genome expansion and contraction in flowering plants. Genetica 115:29-36

Bennetzen JL (2005) Transposable elements, gene creation and genome rearrangement in flowering plants. Current Opinion in Genetics \& Development 15:621-627 
Berenyi MS, Gichuki T, Schmidt J, Burg K (2002) Tyl-copia retrotransposon-based S-SAP (sequence-specific amplified polymorphism) for genetic analysis of sweet potato. Theoretical and Applied Genetics 105:862-869

Biemont C, Vieira C (2006) Junk DNA as an evolutionary force. Nature 443:521-524

Costa AP, Scortecci KC, Hashimoto RY, Araujo PG, Grandbastien M-A, Van Sluys M-A (1999) Retrolyc1-1, a member of the Tntl retrotransposon super-family in the Lycopersicon peruvianum genome. Genetica 107:65-72

Djian-Caporalino C, Lefebvre V, Sage-Daubèze AM, Palloix A (2006) Capsicum. In: Singh RJ (ed) Genetic Resources, Chromosome Engineering, and Crop Improvement series. CRC Press, Florida, pp 185-243

Ellis THN, Poyser SJ, Knox MR, Vershinin AV, Ambrose MJ (1998) Polymorphism of insertion sites of Ty1-copia class retrotransposons and its use for linkage and diversity analysis in pea. Molecular and General Genetics 260:9-19

Eshbaugh WH, Guttman SL, McLeod M (1983) The origin and evolution of domesticated Capsicum species. Ethnobiology 3:49-54

Falush D, Stephens D, Pritchard JK (2007) Inference of population structure using multilocus genotype data: dominant markers and null alleles. Molecular Ecology Notes 7:574-578

Geleta LF, Labuschagne MT, Viljoen CD (2005) Genetic variability in pepper (Capsicum annuum L.) estimated by morphological data and Amplified Fragment Length Polymorphism Markers. Biodiversity and Conservation 14:2361-2375

Grandbastien M-A, Spielmann A, Caboche M (1989) Tnt1, a mobile retroviral-like transposable element of tobacco isolated by plant cell genetics. Nature 26:376-380

Gribbon BM, Pearce SR, Kalendar R, Schulman AH, Paulin L, Jack P, Kumar A, Flavell AJ (1999) Phylogeny and transpositional activity of Tyl-copia group retrotransposons in cereal genomes. Molecular and General Genetics 261:883-891 


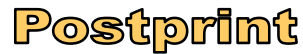

Version définitive du manuscrit publié dans / Final version of the manuscript published in : Theoretical and Applied Genetics, 2009, vol.119, no.6, pp 973-989. DOI:10.1007/s00122-009-1102-6

Hammer K, Arrowsmith N, Gladis T (2003) Agrobiodiversity with emphasis on plant genetic resources. Naturwissenschaften 90:241-250

Hawkins JS, Kim H, Nason JD, Wing RA, Wendel JF (2006) Differential lineage-specific amplification of transposable elements is responsible for genome size variation in Gossypium. Genome Research 16:1252-1261

Huson DH, Bryant D (2006) Application of phylogenetic networks in evolutionary studies. Molecular Biology and Evolution 23:254-267

IPGRI, AVRDC, CATIE (1995) Descriptors for Capsicum (Capsicum spp.). International Plant Genetic Resources Institute, Rome, Italy; the Asian Vegetable Research and Development Center, Taipei, Taiwan; and the Centro Agronomico Tropical de Investigacion y Ensenanza, Turrialba, Costa Rica.

Kalendar R, Grob T, Regina M, Suomeni A, Schulman AH (1999) IRAP and REMAP: two new retrotransposon-based DNA fingerprinting techniques. Theoretical and Applied Genetics 98:704711

Kalendar R, Schulmann AH (2006) IRAP and REMAP for retrotransposon-based genotyping and fingerprinting. Nature Protocols 1:2478-2484

Kashkush K, Feldman M, Levy AA (2003) Transcriptional activation of retrotransposons alters the expression of adjacent genes in wheat. Nature Genetics 33:102-106

Kitching IJ, Forey PL, Humphries CJ, Williams DM (1998) Cladistics: The Theory and Practice of Parsimony Analysis, Second edn. Oxford University Press, Oxford

Kwon YS, Lee JM, Yi GB, Yi SI, Kim KM, Soh EH, Bae KM, Park EK, Song IH, Kim BD (2005) Use of SSR markers to complement tests of distinctiveness, uniformity, and stability (DUS) of pepper (Capsicum annuum L.) varieties. Molecular Cells 19:428-435

Lanteri S, Acquadro A, Quagliotti L, Portis E (2003) RAPD and AFLP assessment of genetic variation in a landrace of pepper (Capsicum annuum L.) grown in North-West Italy. Genetic Resources and Crop Evolution 50:723-735 
Lefebvre V (2005) Molecular markers for genetics and breeding: development and use in pepper (Capsicum spp.). In: Lörz H, Wenzel G (eds) Molecular marker systems in plant breeding and crop improvement Biotechnology in agriculture and forestry. Springer, Berlin, pp 189-214

Lefebvre V, Goffinet B, Chauvet JC, Caromel B, Signoret P, Brand R, Palloix A (2001) Evaluation of genetic distances between pepper inbred lines for cultivar protection purposes: comparison of AFLP, RAPD and phenotypic data. Theoretical and Applied Genetics 102:741-750

Lefebvre V, Palloix A, Rives M (1993) Nuclear RFLP between pepper cultivars (Capsicum annuum L.). Euphytica 71 189-199

Leigh F, Kalendar R, Lea V, Lee D, Donini P, Schulman AH (2003) Comparison of the utility of barley retrotransposon families for genetic analysis by molecular marker techniques. Molecular Genetics and Genomics 269:464-474

Liedloff A (1999) Mantel Nonparametric Test Calculator, Version 2.0. Queensland University of Technology, Brisbane

Livingstone KD, Lackney VK, Blauth JR, van Wijk R, Jahn MK (1999) Genome mapping in Capsicum and the evolution of genome structure in the Solanaceae. Genetics 152:1183-1202

Manetti M, Rossi M, Costa A, Clausen A, Van Sluys M-A (2007) Radiation of the Tnt1 retrotransposon superfamily in three Solanaceae genera. BMC Evolutionary Biology 7

McLeod MJ, Guttman SI, Eshbaugh WH (1982) Early evolution of chili peppers (Capsicum). Economic Botany 36:361-368

Melayah D, Lim KY, Bonnivard E, Chalhoub B, Dorlhac de Borne F, Mhiri C, Leitch AR, Grandbastien M-A (2004) Distribution of the Tnt1 retrotransposon family in the amphidiploid tobacco (Nicotiana tabacum) and its wild Nicotiana relatives. Biological Journal of the Linnean Society 82:639-649

Morgan MT (2001) Transposable element number in mixed mating populations. Genetical Research $77: 261-275$ 
Morrison DA (2005) Networks in phylogenetic analysis: new tools for population biology. International Journal for Parasitology 35:567-582

Moscone EA, Baranyi M, Ebert I, Greilhuber J, Ehrendorfer F, Hunziker AT (2003) Analysis of nuclear DNA content in Capsicum (Solanaceae) by flow cytometry and Feulgen densitometry. Annals of Botany 92 21-29

Nagy I, Stagel A, Sasvari Z, Roder M, Ganal M (2007) Development, characterization, and transferability to other Solanaceae of microsatellite markers in pepper (Capsicum annuum L.). Genome 50:668-688

Nei M (1973) Analysis of gene diversity in subdivided populations. Proceedings of the National Academy of Sciences of the United States of America 70:3321-3323

Neumann P, Koblizkova A, Navratilova A, Macas J (2006) Significant Expansion of Vicia pannonica genome size mediated by amplification of a single type of giant retroelement. Genetics 173:1047-1056

Onus AN, Pickersgill B (2004) Unilateral Incompatability in Capsicum (Solanaceae): Occurrence and taxonomic distribution. Annals of Botany 94:289-295

Paran I, Aftergoot E, Shifriss C (1998) Variation in Capsicum annuum revealed by RAPD and AFLP markers. Euphytica 99:167-173

Park Y-K, Park K-C, Park C-H, Kim N-S (2000) Chromosomal localization and sequence variation of 5S rDNA gene in five Capsicum species. Molecular Cells 10:18-24

Pearce SR, Knox M, Ellis THN, Flavell AJ, Kumar A (2000) Pea Ty1-copia group retrotransposons: transpositional activity and use as markers to study genetic diversity in Pisum. Molecular and General Genetics 263:898-907

Petit M, Lim KY, Julio E, Poncet C, Dorlhac de Borne F, Kovarik A, Leitch AR, Grandbastien MA, Mhiri C (2007) Differential impact of retrotransposon populations on the genome of allotetraploid tobacco (Nicotiana tabacum). Molecular Genetics and Genomics 278:1-15 
Pickersgill B (1997) Genetic resources and breeding of Capsicum spp. Euphytica 96:129-133

Porceddu A, Albertini E, Barcaccia G, Marconi G, Bertoli FB, Veronesi F (2002) Development of S-SAP markers based on an LTR-like sequence from Medicago sativa L. Molecular Genetics and Genomics 267:107-114

Pritchard JK, Stephens M, Donnelly PJ (2000) Inference of population structure using multilocus genotype data. Genetics 155:945-959

Purvis A, Rambaut A (1995) Comparative analysis by independent contrasts (CAIC): an Apple Macintosh application for analysing comparative data. Computer Applications in the Biosciences $11: 247-251$

Ribeiro-Carvalho C, Guedes-Pinto H, Igrejas G, Stephenson P, Schwarzacher T, Heslop-Harrison JS (2004) High levels of genetic diversity throughout the range of the Portuguese wheat landrace 'Barbela'. Annals of Botany 94:699-705

Rodriguez JM, Berke T, Engle L, Nienhuis J (1999) Variation among and within Capsicum species revealed by RAPD markers. Theoretical and Applied Genetics 99:147-156

Rogers SA, Pauls KP (2000) Ty1-copia-like retrotransposons of tomato (Lycopersicon esculentum Mill.). Genome 43:887-894

Saeidi H, Rahiminejad MR, Heslop-Harrison JS (2008) Retroelement insertional polymorphisms, diversity and phylogeography within diploid, D-genome Aegilops tauschii (Triticeae, Poaceae) subtaxa in Iran. Annals of Botany 101:855-861

Sage-Palloix AM, Jourdan F, Phaly T, Nemouchi G, Lefebvre V, Palloix A (2007) Analysis of diversity in pepper genetic resources: distribution of horticultural and resistance traits in the INRA pepper germplasm. In: Niemirowicz-Szczytt K (ed) Progress in research on Capsicum \& Eggplant. Warsaw University of Life Sciences Press, Warsaw

Saitou N, Nei M (1987) The Neighbor Joining method: a new method for reconstructing phylogenetic trees. Molecular Biology and Evolution 4:406-425 
Sniegowski PD, Charlesworth B (1994) Transposable element numbers in cosmopolitan inversions from a natural population of Drosophila melanogaster. Genetics 137:815-827

Swofford DL (2002) PAUP* 4.0 beta 10. Phylogenetic Analysis using Parsimony (and other methods). Sinauer Associates, Sunderland, Massachusetts

Tam SM, Mhiri C, Vogelaar A, Kerkveld M, Pearce S, Grandbastien M-A (2005) Comparative analyses of genetic diversities within tomato and pepper collections detected by retrotransposonbased SSAP, AFLP and SSR. Theoretical and Applied Genetics 110:819-831

Tam SM, Mhiri C, Grandbastien M-A (2007a) Transposable elements and the analysis of plant biodiversity. In: Morot-Gaudry JF, Lea P, Briat J-F (eds) Functional Plant Genomics. Science Publishers, Enfield, pp 529-558

Tam SM, Causse M, Garchery C, Burck H, Mhiri C, Grandbastien M-A (2007b) The distribution of copia-type retrotransposons and the evolutionary history of tomato and related wild species. Journal of Evolutionary Biology 20:1056-1072

Tanksley SD (1984) High rates of cross-pollination in chile pepper. HortScience 19:580-582

Vershinin AV, Allnut TR, Knox MR, Ambrose MJ, Ellis THN (2003) Transposable elements reveal the impact of introgression, rather than transposition in Pisum diversity, evolution and domestication. Molecular Biology and Evolution 20:2067-2075

Walsh BM, Hoot S (2001) Phylogenetic relationships of Capsicum (Solanaceae) using DNA sequences from two noncoding regions: the chloroplast atpB-rbcL spacer region and nuclear waxy introns. International Journal of Plant Sciences 162:1409-1418

Waugh R, McLean K, Flavell AJ, Pearce SR, Kumar A, Thomas BBT, Powell W (1997) Genetic distribution of Bare-1-like retrotransposable elements in the barley genome revealed by sequence specific amplification polymorphisms (SSAP). Molecular and General Genetics 253:687-694

Wright SI, Agrawal N, Bureau TE (2003) Effects of recombination rate and gene density on transposable element distributions in Arabidopsis thaliana. Genome Research 13:1897-1903 
Wright SI, Schoen DJ (1999) Transposon dynamics and the breeding system. Genetica 107:139-148

Yeh FC, Boyle TJB (1997) Population genetic analysis of co-dominant and dominant markers and quantitative traits. Belgian Journal of Botany 129:157

Yu GX, Wise RP (2000) An anchored AFLP- and retrotransposon-based map of diploid Avena. Genome 43:736-749

\section{Figures Captions}

Fig. 1 SSAP-NJ tree and genetic structure of the Capsicum collection. (a) Neighbor Joining SSAP tree (SSAP-NJ) depicting genetic relationships among 86 accessions of seven Capsicum species, based on the combined SSAP dataset obtained from the three primer combinations Tnt1-E00, T135E00 and Tnt1-C00. The SSAP-NJ tree was rooted using the midpoint rooting option. Numbers above branches indicate genetic change values (for the C. annuum accessions see Fig. 3a) and numbers below the branches indicate bootstrap support. (b) Genetic structure of the 86 accessions inferred from Bayesian analysis under the admixture model $\mathrm{K}=5$. The five genetic groups are indicated by white, light grey, dark grey and two diagonally hatched bar contents

Fig. 2 NeighborNet (NN) SSAP tree of the of the Capsicum collection. The NeighborNet (NN) SSAP tree depicts genetic relationships among 86 accessions of seven Capsicum species, based on the combined SSAP dataset obtained from the three Tnt1-E00, T135-E00 and Tnt1-C00 primer combinations 
Fig. 3 SSAP-NJ and genetic structure of the Capsicum annuum collection. (a) Detail of the

Neighbor Joining SSAP tree (SSAP-NJ) shown in Fig. 1a, highlighting genetic relationships among 64 accessions of Capsicum annuum. Fruits characteristics are indicated on the left: fruit fruit shapes were coded according to IPGRI, AVRDC and CATIE, and fruit sizes are based on length $\mathrm{x}$ width, small $<11$, medium 11 to 50 and large $>50$. Numbers above branches indicate genetic change values. (b) Genetic structure of the 64 C. annuum accessions inferred from Bayesian analysis under the admixture model $\mathrm{K}=4$. The four genetic groups are indicated by black, white, light grey, and diagonally hatched bar contents

Supplementary Fig. 1 SSAP-NJ tree of the Capsicum collection rooted with C. eximium. The Neighbor Joining SSAP tree (SSAP-NJ) depicts genetic relationships among 86 accessions of seven Capsicum species, based on the combined SSAP dataset obtained from the three primer combinations Tnt1-E00, T135-E00 and Tnt1-C00. The SSAP-NJ tree was rooted with C. eximium based on phylogenetic results from Walsh and Hoot (2001). The numbers above branches indicate bootstrap support 
Table 1 List of Capsicum accessions

\begin{tabular}{|c|c|c|c|c|c|c|c|c|c|c|}
\hline Code & $\begin{array}{l}\text { PM } \\
\text { code }\end{array}$ & Name & $\begin{array}{l}\text { Geographic } \\
\text { origin }\end{array}$ & $\begin{array}{l}\text { Capsaicin } \\
\text { content }\end{array}$ & ${ }^{\mathrm{A}}$ Fruit code ${ }^{\mathrm{a}}$ & $\mathrm{L}^{\mathrm{b}}$ & $\mathrm{W}^{\mathrm{b}}$ & $\mathrm{LxW}^{\mathrm{b}}$ & $\begin{array}{l}\text { Fruit } \\
\text { size }^{c}\end{array}$ & Status $^{\mathrm{d}}$ \\
\hline \multicolumn{11}{|c|}{ Capsicum annuum (64 accessions) } \\
\hline$\overline{\mathrm{C} 01}$ & 31 & Yolo Wonder & USA & sweet & square (1) & 8 & 8.5 & 68 & large & $c$ \\
\hline C02 & 32 & Antibois & France & sweet & spherical (6) & 4 & 6 & 24 & medium & c \\
\hline $\mathrm{C} 03$ & 38 & Cerise & France & pungent & spherical (6) & 1.6 & 2.2 & 3.52 & small & c \\
\hline $\mathrm{C} 04$ & 57 & Doux d'Alger & Algeria & sweet & triangular (3) & 18 & 4 & 72 & large & c \\
\hline $\mathrm{C} 05$ & 69 & Doux d'Espagne & Spain & sweet & triangular (3) & 14 & 6 & 84 & large & c \\
\hline $\mathrm{C} 06$ & 76 & Doux des Landes & France & sweet & elongated (4) & 11 & 2 & 22 & medium & c \\
\hline C07 & 148 & Niora & Spain & sweet & spherical (6) & 3 & 3.5 & 10.5 & small & c \\
\hline $\mathrm{C} 08$ & 162 & Yolo Y = YRP10 & USA & sweet & square (1) & 9 & 7 & 63 & large & c \\
\hline $\mathrm{C} 09$ & 194 & Lamu & France & sweet & rectangular (2) & 13.5 & 6.5 & 87.8 & large & c \\
\hline $\mathrm{C} 10$ & 217 & Piment 493-1 PI201234 & USA-Mexico & pungent & triangular (3) & 7 & 2 & 14 & medium & c \\
\hline C11 & 223 & Pimiento Morron & Spain & sweet & spherical (6) & 6.5 & 6.5 & 42.3 & medium & $c$ \\
\hline C12 & 278 & Largo de Reus & Spain & sweet & rectangular (2) & 14.5 & 6.8 & 98.6 & large & c \\
\hline C13 & 343 & Collectivist 1962 & Russia-Roumania & sweet & square (1) & 8 & 4.5 & 36 & medium & $c$ \\
\hline $\mathrm{C} 14$ & 355 & Nigrum & Serbia & pungent & elongated short (5) & 4 & 2 & 8 & small & c \\
\hline $\mathrm{C} 15$ & 589 & Moura & Brazil & sweet & rectangular (2) & 8.5 & 5 & 42.5 & medium & c \\
\hline $\mathrm{C} 16$ & 597 & Podarok Moldavi & Russie & sweet & heart-shaped (7) & 8.8 & 6.8 & 59.8 & large & c \\
\hline $\mathrm{C} 17$ & 600 & LP1 & USA-Mexico & pungent & elongated short (5) & 3 & 1.2 & 3.6 & small & c \\
\hline $\mathrm{C} 18$ & 602 & Avelar PI342940 & Brazil & sweet & triangular (3) & 9.5 & 5.5 & 52.3 & large & c \\
\hline C19 & 609 & Ancho Esmeralda & Mexico & pungent & triangular (3) & 9.1 & 4 & 36.4 & medium & c \\
\hline $\mathrm{C} 20$ & 610 & Jalapeno Rayado & Mexico & pungent & elongated short (5) & 5.5 & 3 & 16.5 & medium & c \\
\hline $\mathrm{C} 21$ & 611 & Mulato Roque & Mexico & pungent & triangular (3) & 9.2 & 4.6 & 42.3 & medium & c \\
\hline C22 & 612 & Passilla Apaseo & Mexico & pungent & elongated (4) & 13.2 & 1.7 & 22.4 & medium & c \\
\hline $\mathrm{C} 23$ & 614 & Serrano Vera Cruz S.69 & Mexico & pungent & elongated short (5) & 4.5 & 1.5 & 6.75 & small & c \\
\hline C24 & 621 & Agronomico 10-G & Brazil & sweet & rectangular (2) & 10.8 & 6.2 & 67 & large & c \\
\hline $\mathrm{C} 25$ & 641 & Turrialba (C81) (var glabriusculum) & Costa Rica & pungent & elongated short (5) & 1.2 & 0.8 & 0.96 & small & wild \\
\hline $\mathrm{C} 26$ & 659 & Perennial & India & pungent & elongated short (5) & 4 & 0.7 & 2.8 & small & C \\
\hline $\mathrm{C} 27$ & 662 & S20-1 Singh4 & India & pungent & elongated short (5) & 5 & 1.3 & 6.5 & small & c \\
\hline $\mathrm{C} 28$ & 687 & PI 322719 & India & pungent & rectangular (2) & 6.5 & 3.5 & 22.8 & medium & c \\
\hline $\mathrm{C} 29$ & 691 & Florida VR2 & USA & sweet & square (1) & 8 & 7 & 56 & large & c \\
\hline C30 & 702 & Serrano Criollo de Morelos 334 & Mexico & pungent & elongated short (5) & 6 & 2 & 12 & medium & c \\
\hline C31 & 703 & Flambeau SM477P & Tunisia & pungent & elongated short (5) & 6 & 2.3 & 13.8 & medium & $c$ \\
\hline C32 & 721 & Morales PRV121 "Mora" & Mexico & pungent & elongated short (5) & 6 & 1 & 6 & small & $c$ \\
\hline C33 & 747 & Incesu 18 & Turquey & pungent & elongated (4) & 20.5 & 1.8 & 36.9 & medium & c \\
\hline C34 & 750 & Carliston 52 & Turquey & sweet & triangular $(3)$ & 11.9 & 3.2 & 38.1 & medium & $c$ \\
\hline C35 & 775 & Benxi & China & sweet & square (1) & 5.5 & 7.5 & 41.3 & medium & $c$ \\
\hline C36 & 799 & Novi 3 & Netherlands & sweet & square (1) & 9.5 & 8 & 76 & large & $c$ \\
\hline $\mathrm{C} 37$ & 807 & $\mathrm{H} 3$ & Ethiopia & pungent & elongated (4) & 10 & 2.4 & 24 & medium & $C$ \\
\hline C38 & 960 & F1 Zhongjiao $\mathrm{N}^{\circ} 4$ & China & sweet & square (1) & 7.5 & 8 & 60 & large & $c$ \\
\hline C39 & 973 & Carre d'Asti Jaune & Italia & sweet & square (1) & 13 & 9 & 117 & large & c \\
\hline $\mathrm{C} 40$ & 1005 & Noras & Spain & sweet & spherical (6) & 4 & 5.4 & 21.6 & medium & c \\
\hline $\mathrm{C} 42$ & 1012 & $\mathrm{SC} 81$ & Cuba & sweet & triangular (3) & 8.5 & 3 & 25.5 & medium & $C$ \\
\hline C45 & 1041 & PLOO71-Cuneo & Italia & sweet & square (1) & 7.5 & 9 & 67.5 & large & $c$ \\
\hline C46 & 1053 & Doux Long Lombardie & Italia & sweet & elongated (4) & 10 & 2 & 20 & medium & $c$ \\
\hline C47 & 1066 & Chile de Arbol & Mexico & pungent & elongated (4) & 9.7 & 1 & 9.7 & small & c \\
\hline C48 & 1072 & Lamu VR2 & France & sweet & rectangular (2) & 17.5 & 8 & 140 & large & c \\
\hline $\mathrm{C} 50$ & 1086 & $N^{\circ} 1106=$ Serang & Indonesia & pungent & elongated (4) & 13 & 2.3 & 29.9 & medium & c \\
\hline C51 & 1107 & Kahramanmaras & Turquey & pungent & triangular (3) & 8 & 2.5 & 20 & medium & c \\
\hline C52 & 1109 & Piquin (var glabriusculum) & Mexico & pungent & elongated short (5) & 1.5 & 0.6 & 0.9 & small & wild \\
\hline C53 & 1125 & 2112B58 & Korea & pungent & elongated (4) & 7.8 & 1.8 & 14 & medium & c \\
\hline C54 & 1166 & Early California Wonder (ECW) & USA & sweet & square (1) & 5.5 & 7 & 38.5 & medium & c \\
\hline $\mathrm{C} 55$ & 1172 & $12 \mathrm{HD}$ & descent $\mathrm{C} 01 \times \mathrm{C} 09$ & sweet & triangular (3) & 16 & 3.2 & 51.2 & large & $C$ \\
\hline C56 & 1194 & Saint Remy 1 & France & sweet & rectangular (2) & 8 & 4 & 32 & medium & $c$ \\
\hline C57 & 1202 & Penis Shape & - & pungent & elongated (4) & 7 & 2.5 & 17.5 & medium & $c$ \\
\hline C58 & 1204 & Numex Twilight & USA & pungent & elongated short (5) & 2.5 & 1.2 & 3 & small & c \\
\hline C59 & 1210 & Poivron d'Ampuis & France & sweet & square (1) & 4.5 & 4 & 18 & medium & c \\
\hline C60 & 1215 & Beldi & Tunisia & pungent & elongated (4) & 10.5 & 3.5 & 36.8 & medium & $c$ \\
\hline C61 & 1361 & PYC22 & India & pungent & elongated (4) & 8 & 3.6 & 28.8 & medium & C \\
\hline C62 & 1406 & HDA 801 & descent $\mathrm{C} 29 \mathrm{xC} 26$ & pungent & rectangular (2) & 7.5 & 3 & 22.5 & medium & $c$ \\
\hline C63 & 1407 & Phyo 636 & descent $\mathrm{C} 01 \mathrm{xC} 10$ & sweet & rectangular (2) & 13.2 & 4.8 & 63.4 & large & $c$ \\
\hline C64 & 1408 & Milord & France & sweet & rectangular (2) & 10.3 & 6.5 & 67 & large & c \\
\hline C65 & 1409 & Vania & France & sweet & rectangular (2) & 9.5 & 6.5 & 61.8 & large & c \\
\hline C66 & 1410 & HDA 103 & descent $\mathrm{C} 01 \mathrm{xC} 28$ & pungent & rectangular (2) & 8.5 & 6.5 & 55.3 & large & c \\
\hline C68 & 1412 & Bastidon & France & sweet & rectangular (2) & 15 & 7.5 & 113 & large & c \\
\hline C69 & 1486 & Brûlant d'Espagne & Spain & pungent & spherical (6) & 3.6 & 3.2 & 11.5 & medium & $c$ \\
\hline \multicolumn{11}{|c|}{ Capsicum baccatum ( 8 accessions) } \\
\hline $\mathrm{C} 70$ & 319 & PEN2 (var pendulum) & & & & 10 & 2 & 20 & medium & $C$ \\
\hline C71 & 325 & PEN3-4 (var pendulum) & Peru-Bolivia & pungent & elongated (4) & 5.5 & 1 & 5.5 & small & c \\
\hline
\end{tabular}


Version définitive du manuscrit publié dans / Final version of the manuscript published in : Theoretical and Applied Genetics, 2009, vol.119, no.6, pp 973-989. DOI:10.1007/s00122-009-1102-6

\begin{tabular}{|c|c|c|c|c|c|c|c|c|c|}
\hline $\mathrm{C} 72$ & 1022 Cristal Blanco (var pendulum) & Peru & pungent & elongated (4) & 9.5 & 2.1 & 20 & medium & $C$ \\
\hline C73 & 1026 Muaraparte Rojo (var pendulum) & Peru & pungent & elongated (4) & 16 & 1.8 & 28.8 & medium & C \\
\hline C74 & 1203 Christmas Bell (var pendulum) & Peru-Bolivia & pungent & bell shaped (8) & 3 & 6 & 18 & medium & $C$ \\
\hline $\mathrm{C} 75$ & 1321 PI 439399 (var pendulum) & Peru & pungent & elongated (4) & 12 & 2.8 & 33.6 & medium & C \\
\hline C76 & 1324 PI 439402 (var pendulum) & Peru & pungent & elongated (4) & 18.5 & 2 & 37 & medium & C \\
\hline C91 & 441 SA 326 (var baccatum) & Peru-Bolivia & pungent & elongated short (5) & 1 & 0.5 & 0.5 & small & wild \\
\hline \multicolumn{10}{|c|}{ Capsicum chacoense (1 accession) } \\
\hline $\mathrm{C} 78$ & 1265 PI260429 & Bolivia-Paraguay & pungent & elongated short (5) & 0.9 & 0.7 & 0.63 & small & wild \\
\hline \multicolumn{10}{|c|}{ Capsicum chinense (5 accessions) } \\
\hline$\overline{\mathrm{C} 79}$ & 577 PI 159236 & USA & pungent & elongated (4) & 11 & 2.5 & 27.5 & medium & $c$ \\
\hline $\mathrm{C} 80$ & 967 Diego & Madagascar & pungent & bell shaped (8) & 3 & 3 & 9 & small & C \\
\hline C81 & 987 Baili & Tchad & pungent & bell shaped (8) & 4.5 & 4 & 18 & medium & $C$ \\
\hline $\mathrm{C} 82$ & 1093 Chile Habanero (Merida) & Mexico & pungent & bell shaped (8) & 5.1 & 4 & 20.4 & medium & $C$ \\
\hline$\underline{\mathrm{C} 83}$ & 1363 Notto & Senegal & pungent & bell shaped (8) & 5 & 5.5 & 27.5 & medium & $C$ \\
\hline \multicolumn{10}{|c|}{ Capsicum eximium (1 accession) } \\
\hline$\underline{\mathrm{C} 85}$ & $1372 \mathrm{EXI} 2$ & Bolivia & pungent & elongated short (5) & 1 & 0.5 & 0.5 & small & wild \\
\hline \multicolumn{10}{|c|}{ Capsicum frutescens (5 accessions) } \\
\hline$\overline{\mathrm{C} 86}$ & 153 Tabasco & USA & pungent & elongated short (5) & 4 & 1.5 & 6 & small & $C$ \\
\hline C87 & 262 Filo & Burkina Fasso & pungent & elongated short (5) & 2 & 0.7 & 1.4 & small & C \\
\hline C88 & 330 Grain de Café & Central America & pungent & elongated short (5) & 2.5 & 1.2 & 3 & small & C \\
\hline C89 & 357 FRU $7(=\mathrm{CHI} 7)^{\mathrm{e}}$ & Caribeans & pungent & elongated short (5) & 5 & 2.5 & 12.5 & medium & $C$ \\
\hline$\underline{\mathrm{C} 90}$ & 1108 Charlette & Central America & pungent & elongated short (5) & 3.3 & 0.9 & 2.97 & small & $C$ \\
\hline \multicolumn{10}{|c|}{ Capsicum pubescens (2 accessions) } \\
\hline $\mathrm{C} 92$ & 374 Rocoto REG 502 & Peru & pungent & spherical (6) & 3.5 & 3.8 & 13.3 & medium & $C$ \\
\hline C93 & $115754 \mathrm{P}$ & Peru & pungent & spherical (6) & 4.8 & 4.5 & 21.6 & medium & $C$ \\
\hline
\end{tabular}

${ }^{a}$ Fruit types codified according to IPGRI, AVRDC and CATIE $(1995) ;{ }^{b} \mathrm{~L}=$ fruit lenth, $\mathrm{W}=$ fruit width, $\mathrm{LxW}=$ fruit length $\mathrm{x}$ fruit width; ${ }^{\mathrm{c}}$ Fruit sizes classified according to $\mathrm{Lx} \mathrm{W}$ : small $=<11$, medium $=11$ to 50 , large $=>50 ;{ }^{\mathrm{d}} \mathrm{c}=$ cultivated; $^{\mathrm{e}}$ Reclassified as $C$. chinense by the present study.

Table 2 SSAP data observed from across the 86 Capsicum accessions

\begin{tabular}{lllll}
\hline & Tnt1- & Tnt1- & T135- & Combined \\
& C00 & E00 & E00 & \\
\hline Nb bands scored & 95 & 50 & 50 & 195 \\
Nb polymorphic bands & 95 & 50 & 47 & 192 \\
\% polymorphic bands & 100 & 100 & 94 & 98.46 \\
Nb species-specific bands & 11 & 7 & 6 & 24 \\
\% species-specific bands & 11.58 & 14 & 12 & 12.3 \\
\hline
\end{tabular}

Table 3 Genetic structure analyses based on Bayesian partitioning of ancestry

\begin{tabular}{|c|c|c|c|}
\hline & $\mathrm{K}^{\mathrm{a}}$ & $\begin{array}{l}\text { Likelihood value } \\
\text { LnP(D) }\end{array}$ & $\begin{array}{l}\text { Variance } \\
\text { of } \operatorname{LnP}(\mathrm{D})\end{array}$ \\
\hline \multirow[t]{10}{*}{ Seven Capsicum species (86 accessions) } & 1 & -8731.95 & 546 \\
\hline & 2 & -6298.55 & 1080.4 \\
\hline & 3 & -5468.5 & 1217.45 \\
\hline & 4 & -5263.65 & 1436.6 \\
\hline & 5 & -5204.05 & 1708.55 \\
\hline & 6 & -5407.15 & 2136.15 \\
\hline & 7 & -5558.3 & 2679.25 \\
\hline & 8 & -5841 & 2943.95 \\
\hline & 9 & -6324.2 & 4425.7 \\
\hline & 10 & -6529.9 & 4256.9 \\
\hline \multirow[t]{7}{*}{ Capsicum annuum (64 accessions) } & 1 & -3246.6 & 655.6 \\
\hline & 2 & -3218.5 & 946.7 \\
\hline & 3 & -2970.7 & 970.03 \\
\hline & 4 & -2886.67 & 1076.47 \\
\hline & 5 & -2928.4 & 1267.1 \\
\hline & 6 & -2851.75 & 1161.85 \\
\hline & 7 & -2939.15 & 1103.95 \\
\hline
\end{tabular}

\footnotetext{
${ }^{a} \mathrm{~K}=$ theoretical number of populations; for seven Capsicum species, $\mathrm{K}=1-10$ were tested; for C. annuum, $\mathrm{K}=1-22$ were tested,
} however $\mathrm{K}>7$ data are not shown, as no significant improvement was detected 
Table 4 Genetic diversity values of Capsicum species

\begin{tabular}{|c|c|c|c|c|c|c|c|}
\hline Capsicum species & annuum & baccatum & chacoense & chinense & eximium & frutescens & pubescens \\
\hline $\mathrm{Nb}$ accessions & 64 & 8 & 1 & 5 & 1 & 5 & 2 \\
\hline \multicolumn{8}{|l|}{ Individual datasets: } \\
\hline \multicolumn{8}{|l|}{ Tnt1-C00 } \\
\hline $\mathrm{Nb}$ bands scored & 63 & 48 & 39 & 38 & 36 & 65 & 30 \\
\hline $\mathrm{Nb}$ polymorphic bands & 55 & 26 & - & 14 & - & 52 & 5 \\
\hline$\%$ polymorphism & 87.3 & 54.17 & - & 36.84 & - & 80 & 16.67 \\
\hline $\mathrm{H}_{\mathrm{e}}$ & 0.1878 & 0.2003 & - & 0.1404 & - & 0.2921 & 0.069 \\
\hline Average nb of bands/accession & 33.12 & 36.5 & 39 & 31.2 & 36 & 37.8 & 27.5 \\
\hline Standard deviation & 2.585 & 1.512 & - & 1.095 & - & 4.147 & 0.707 \\
\hline \multicolumn{8}{|l|}{ T135-E00 } \\
\hline $\mathrm{Nb}$ bands scored & 35 & 33 & 18 & 26 & 17 & 32 & 21 \\
\hline $\mathrm{Nb}$ polymorphic bands & 26 & 18 & - & 12 & - & 21 & 5 \\
\hline$\%$ polymorphism & 74.29 & 54.55 & - & 46.15 & - & 65.62 & 23.81 \\
\hline $\mathrm{H}_{\mathrm{e}}$ & 0.2064 & 0.1724 & - & 0.1716 & - & 0.2463 & 0.0986 \\
\hline Average $\mathrm{nb}$ of bands/accession & 22.39 & 23.75 & 18 & 19.8 & 17 & 21.4 & 18.5 \\
\hline Standard deviation & 2.090 & 1.389 & - & 1.304 & - & 3.05 & 0.707 \\
\hline \multicolumn{8}{|l|}{ Tnt1-E00: } \\
\hline $\mathrm{Nb}$ bands scored & 32 & 24 & 16 & 20 & 17 & 25 & 19 \\
\hline $\mathrm{Nb}$ polymorphic bands & 26 & 19 & - & 13 & - & 20 & 4 \\
\hline$\%$ polymorphism & 81.25 & 79.17 & - & 65 & - & 80 & 21.05 \\
\hline $\mathrm{H}_{\mathrm{e}}$ & 0.1378 & 0.3054 & - & 0.2341 & - & 0.2710 & 0.0872 \\
\hline Average $\mathrm{nb}$ of bands/accession & 13.53 & 16.5 & 16 & 13.2 & 17 & 13.4 & 17 \\
\hline Standard deviation & 1.736 & 2.39 & - & 0.837 & - & 2.191 & 0 \\
\hline \multicolumn{8}{|l|}{ Combined dataset } \\
\hline $\mathrm{Nb}$ bands scored & 130 & 105 & 73 & 84 & 70 & 122 & 70 \\
\hline $\mathrm{Nb}$ polymorphic bands & 107 & 63 & - & 39 & - & 93 & 14 \\
\hline$\%$ polymorphism & 82.31 & 60 & - & 46.43 & - & 76.23 & 20 \\
\hline $\mathrm{H}_{\mathrm{e}}$ & 0.1805 & 0.2156 & - & 0.1724 & - & 0.2758 & 0.0828 \\
\hline \multicolumn{8}{|l|}{ Genetic distances (gd): all accessions } \\
\hline Mean gd & 0.146 & 0.218 & - & 0.233 & - & 0.390 & - \\
\hline Max gd & 0.409 & 0.390 & - & 0.321 & - & 0.557 & - \\
\hline Min gd & 0.0236 & 0.0667 & - & 0.107 & - & 0.189 & - \\
\hline Mean sampling variance & 0.00094 & 0.00154 & - & 0.00205 & - & 0.00183 & - \\
\hline \multicolumn{8}{|l|}{ Genetic distances (gd): pungent chillis } \\
\hline Mean gd & 0.170 & - & - & - & - & - & - \\
\hline Mean sampling variance & 0.00111 & - & - & - & - & - & - \\
\hline \multicolumn{8}{|l|}{ Genetic distances (gd): sweet peppers } \\
\hline Mean gd & 0.141 & - & - & - & - & - & - \\
\hline Mean sampling variance & 0.00109 & - & - & - & - & - & - \\
\hline
\end{tabular}

Table 5 Estimate of relationships between parameters obtained from Phylogenetic Independant Contrasts

\begin{tabular}{|c|c|c|c|c|c|c|}
\hline \multirow[b]{2}{*}{ Relationships between: } & \multicolumn{2}{|c|}{ Tnt1-C00 } & \multicolumn{2}{|c|}{ T135-E00 } & \multicolumn{2}{|c|}{ Tnt1-E00 } \\
\hline & $\mathrm{P}^{\mathrm{a}}$ & $\mathrm{m}^{\mathrm{b}}$ & $\mathrm{P}^{\mathrm{a}}$ & $\mathrm{m}^{\mathrm{b}}$ & $\mathrm{P}^{\mathrm{a}}$ & $\mathrm{m}^{\mathrm{b}}$ \\
\hline$\%$ polymorphism and average $\mathrm{nb}$ of bands & 0.1398 & 4.11 & 0.0837 & 3.48 & 0.3478 & 3.22 \\
\hline $\mathrm{H}_{\mathrm{e}}$ and average $\mathrm{nb}$ bands & 0.0071 & 0.02 & 0.1871 & 0.02 & 0.9173 & 0.0042 \\
\hline
\end{tabular}




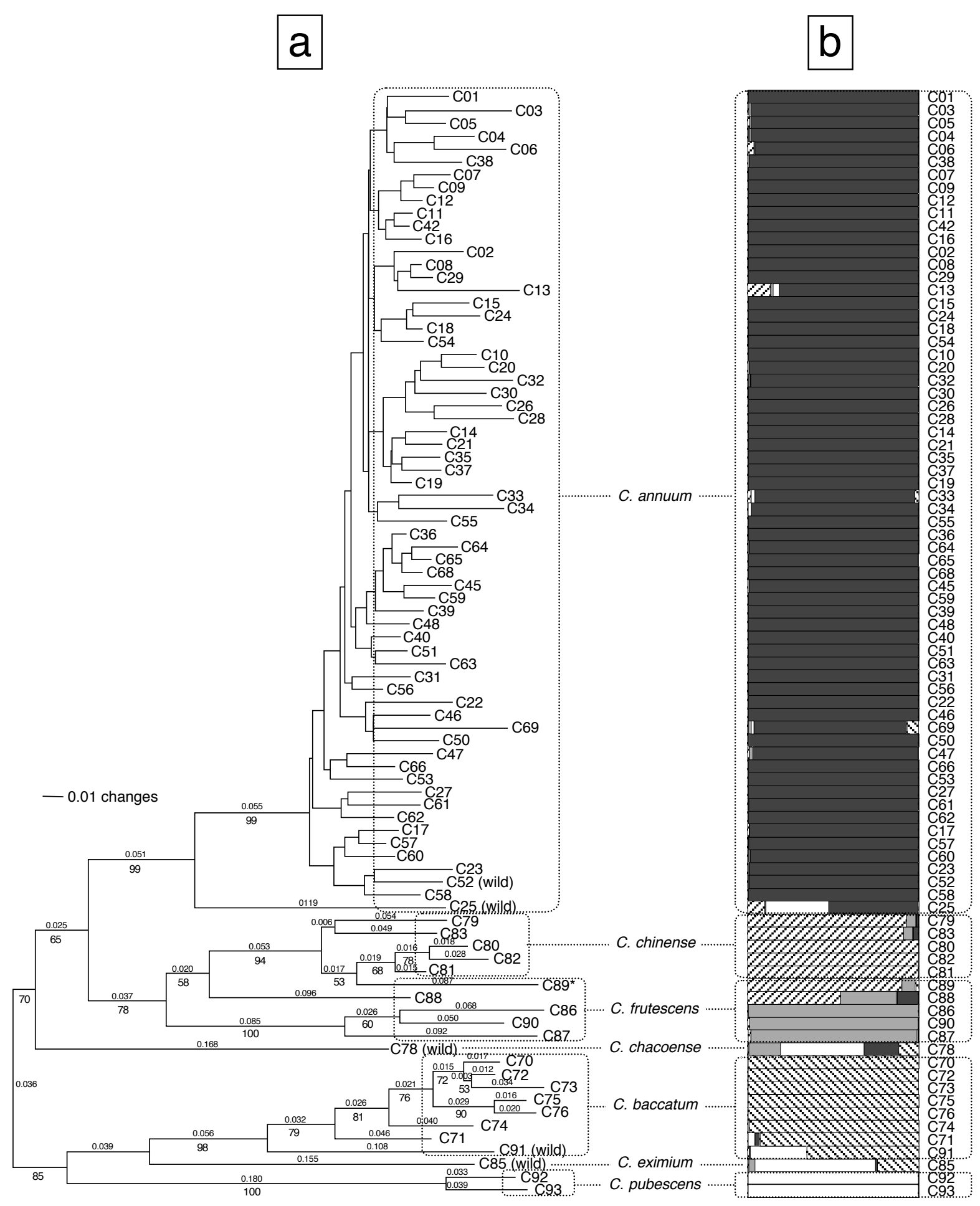




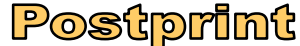

Version définitive du manuscrit publié dans / Final version of the manuscript published in : Theoretical and Applied Genetics, 2009, vol.119, no.6, pp 973-989. DOI:10.1007/s00122-009-1102-6

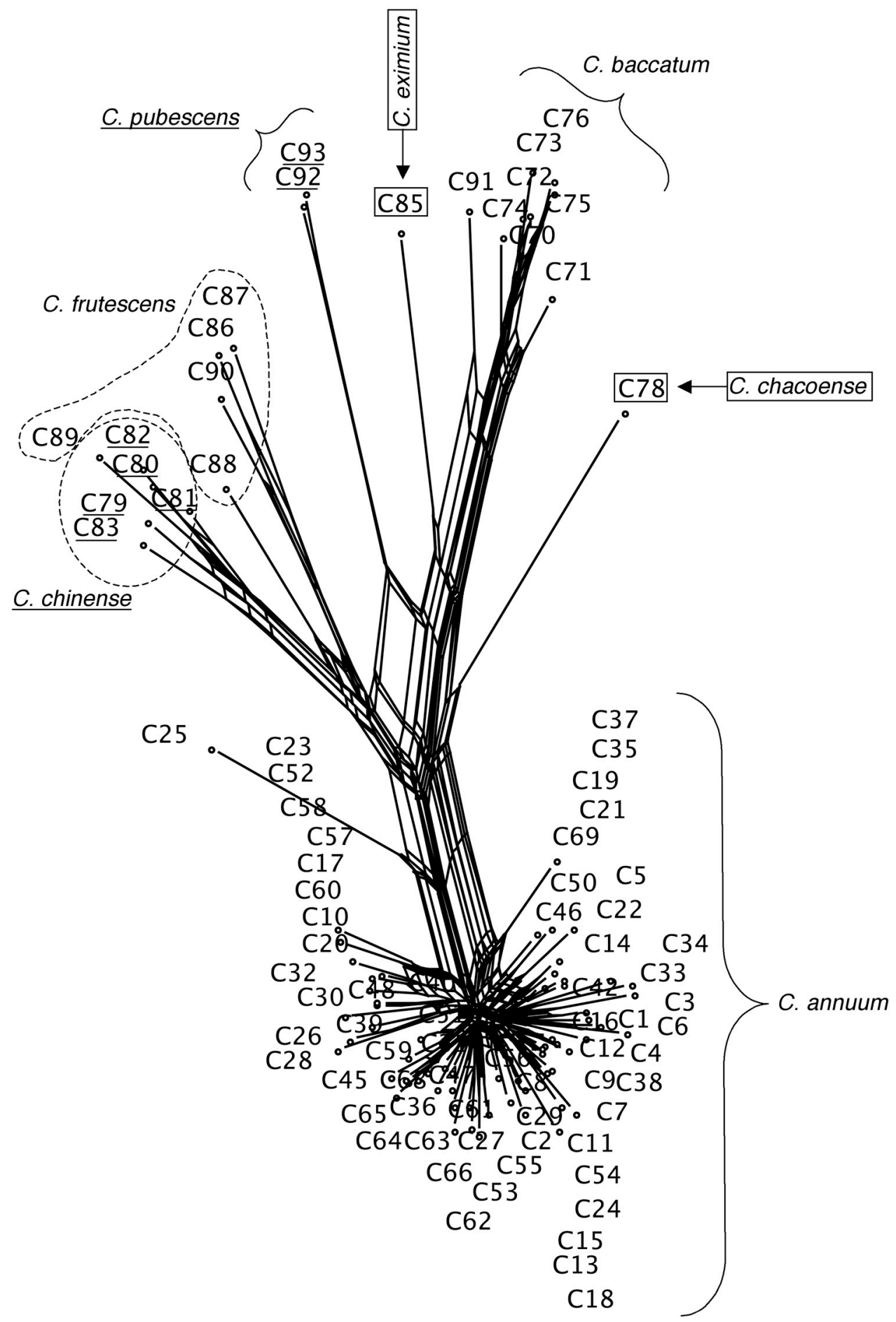

$\mapsto 0.01$ changes 


\begin{tabular}{|c|}
\hline Fruit characteristics: \\
\hline Pungency: $\begin{array}{c}\text { Cxy sweet } \\
\text { (Cxy hot }\end{array}$ \\
\hline 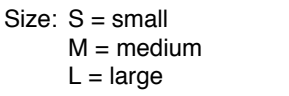 \\
\hline Code: $\begin{aligned} 1 & =\text { square } \\
2 & =\text { rectangular } \\
3 & =\text { triangular } \\
4 & =\text { elongated } \\
5 & =\text { elongated short } \\
6 & =\text { spherical } \\
7 & =\text { heart }- \text { shaped } \\
8 & =\text { bell-shaped }\end{aligned}$ \\
\hline
\end{tabular}
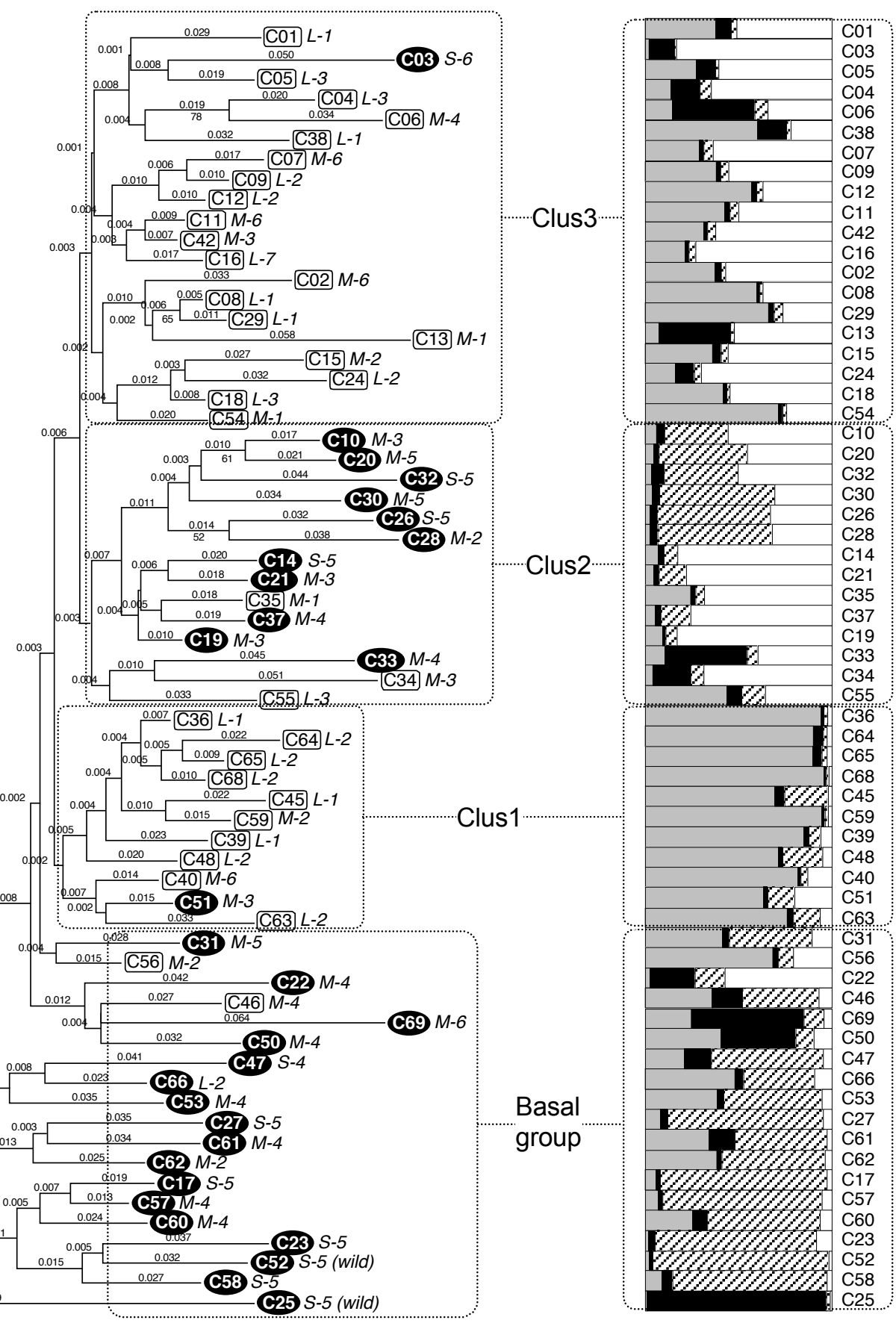